\title{
Non-contact em measurement of the properties of power station steels taken from service
}

DOI:

10.1109/I2MTC.2013.6555679

Link to publication record in Manchester Research Explorer

\section{Citation for published version (APA):}

Karimian, N., Yin, W., Liu, J., Hao, XJ., Strangwood, M., Davis, CL., \& Peyton, AJ. (2013). Non-contact em measurement of the properties of power station steels taken from service. In host publication (pp. 1573-1578). IEEE. https://doi.org/10.1109//2MTC.2013.6555679

\section{Published in:}

host publication

\section{Citing this paper}

Please note that where the full-text provided on Manchester Research Explorer is the Author Accepted Manuscript or Proof version this may differ from the final Published version. If citing, it is advised that you check and use the publisher's definitive version.

\section{General rights}

Copyright and moral rights for the publications made accessible in the Research Explorer are retained by the authors and/or other copyright owners and it is a condition of accessing publications that users recognise and abide by the legal requirements associated with these rights.

\section{Takedown policy}

If you believe that this document breaches copyright please refer to the University of Manchester's Takedown Procedures [http://man.ac.uk/04Y6Bo] or contact uml.scholarlycommunications@manchester.ac.uk providing relevant details, so we can investigate your claim.

\section{OPEN ACCESS}




\title{
Non-Contact EM Measurement of the Properties of Power Station Steels Taken from Service
}

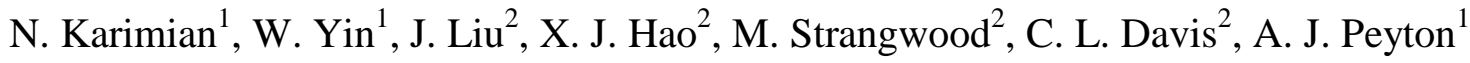 \\ ${ }^{1}$ School of Electrical and Electronic Engineering, University of Manchester, M60 1QD, UK \\ ${ }^{2}$ School of Metallurgy and Materials, University of Birmingham, Edgbaston, Birmingham, B15 2TT, UK \\ Email: Noushin.Karimian@ postgrad.manchester.ac.uk
}

\begin{abstract}
Analysis of the electromagnetic properties of power station steels, measured using a non-contact EM sensor, is of significance as such properties are indicative of the microstructure of the material. In this paper, we present the measurement of cylindrical power station steel samples (namely $P 91$ and $P 9$ grades) in different conditions. Initially the B-H curves of these steel samples were measured. Then printed circuit board (PCB) coil integrated sensors were used to measure the incremental permeability. Analytical and numerical methods (Finite Elements Methods) were employed to calculate the sensor response of these samples. Experimental results were obtained for a range of samples and their electromagnetic properties inferred by fitting finite element models to the measured results.
\end{abstract}

Keywords - Electromagnetic properties, Power station steels, Electromagnetic sensors, FEM, Analytical models

\section{INTRODUCTION}

Measurement of the electromagnetic (EM) properties of materials can be very important; as such properties give an indication of the materials' microstructure (and hence performance) and condition-related parameters. For instance, the permeability and conductivity of porous $\mathrm{Cu}$ and $\mathrm{Fe}$ foams, manufactured by the lost carbonate sintering process, have proven to be related to their porosity [1]. In steels ferrite fraction variations $[2,3,4,5]$, creep damage and precipitation [6] causes changes to EM properties. Factors such as residual stress [7], temperature and case hardening [8] also have an affect on the steels' EM properties. Such EM properties can be obtained through measurement of the material using purpose built EM sensors.

Power generation steel components such as boiler tubes and steam line pipes are exposed to high temperature during their lifetime, and therefore experience carbide coarsening and occurrence of creep cavitation [9]. To the authors' knowledge, no in-situ technique has yet been implemented to directly monitor the changes in microstructure of inservice power station steel components at an elevated temperature. It is worth noting that currently when the P91 steels are incorrectly heat treated to produce an incorrect (ferritic) microstructure, they can be a serious concern today with plant operating e.g. at $550-580^{\circ} \mathrm{C}$. Although this is not seen to be a major problem yet, it may eventually become a serious issue, requiring more frequent and detailed inspections, as future coal-fuelled power stations will be operating at higher temperatures and pressures. Coal-fuelled power stations can currently operate at temperatures of up to $620^{\circ} \mathrm{C}$, but this may increase within the next decade to around $700{ }^{\circ} \mathrm{C}$ for future operations in order to help reduce their carbon dioxide $\left(\mathrm{CO}_{2}\right)$ emissions by up to $25 \%$, and also provide greater efficiency.

Undoubtedly, the ability to monitor these micro-structural changes of steel components through their EM property variation may become very useful. In this paper, a PCB-coil integrated sensor was designed to measure the EM properties of $50 \mathrm{~mm}$ long cylindrical power steel samples simulating different degrees of degradation. Similar research has been completed by measuring different power station steels using cylindrical air-cored sensors $[10,11]$. Surely other sensor geometries for component investigations are also possible. Analytical and numerical methods (finite elements) are used to calculate the sensor response, through which the conductivity and permeability of the samples were inferred. In addition, a sensitivity analysis was also carried out to evaluate the accuracy of the method [10].

\section{METHODOLOGY}

\section{A. Physical Principle}

Any microstructural variation of steel may lead to changes in its EM properties, e.g. relative permeability and conductivity. EM sensors can function on the basis of detecting and identifying a variation of these quantities measured from samples. By measuring the response of such EM sensors over a range of frequencies, the permeability and conductivity of these power station steels can be accurately inferred. 
The effect of eddy currents in the sensor response is very weak at low frequencies, and any contribution to the inductance change is mainly from the magnetisation of the sample. Therefore the inductance measured at the low frequencies is related to the sample permeability. However, the effect of eddy currents in the sample becomes stronger with increase in the frequency; and therefore variation in the inductance is gradually dominated by the effect of conductivity or polarisation delay of the sample. The electric and magnetic properties of the samples can be determined by complete analysis of the inductancefrequency spectra.

\section{B. Experimental Procedure}

Two groups of power generation steels were studied, the first group being P9 steel (8.40Cr-0.97Mo-0.12C$0.52 \mathrm{Si}-0.44 \mathrm{Mn}$ ) removed from a service at $520^{\circ} \mathrm{C}$ for approximately 11 years, the second group being P91. The selected samples which belong to group one (approx. 70 $\mathrm{mm} \times 15 \mathrm{~mm} \times 7 \mathrm{~mm}$ ) were heat treated to simulate the service entry microstructure by normalising at $950^{\circ} \mathrm{C}$ for 1 hour and then tempering at $760^{\circ} \mathrm{C}$ for 1 hour. Asnormalised samples were also examined. Cylindrical rods of $50 \mathrm{~mm}$ long and $4.95 \mathrm{~mm}$ in diameter for each condition were prepared for the EM sensor measurements. The second group of samples consist of 5 samples that have been taken from a piece of P91 pipe that had been in operation for 50,000 hours at temperature of $550^{\circ} \mathrm{C}$. One sample was removed from close to the inner-surface; one sample about $7 \mathrm{~mm}$ off the inner surface and one sample from the bulk part of the pipe. A further two samples were taken from the bulk of the pipe and heat treated by normalising at $1080^{\circ} \mathrm{C}$ for 1 hour followed by tempering at $760^{\circ} \mathrm{C}$ for 1 hour. Figure 1 shows the piece of P91 pipe section with wall thickness of $45 \mathrm{~mm}$ from which the samples have been cut.

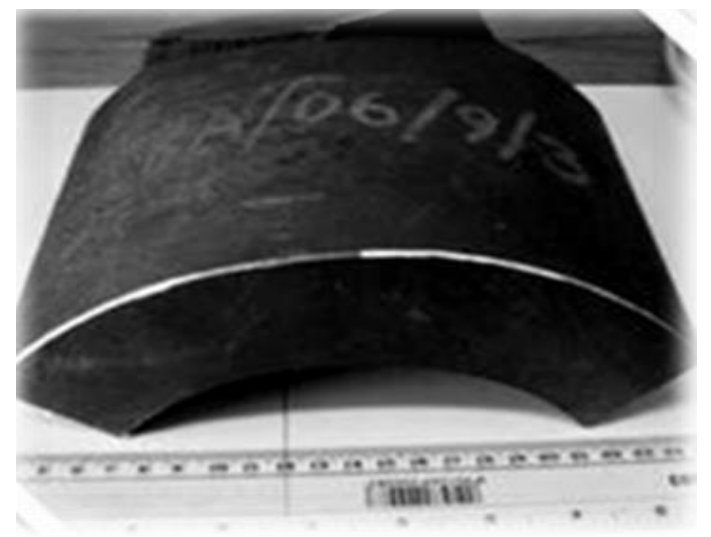

Figure 1. Piece of P91 pipe.

The power station cylindrical rod steel samples were measured by inserting them into an air-cored PCB-coil integrated sensor, which consists of two identical coils arranged as PCB layers on top of each other, one as exciting and the other as receiver. The PCB-coil integrated sensor consists of 12 layers, 6 of which contain the coils for the receiver and the remaining 6 for the transmitter. Each of these 6 layers consists of 6 turns, making an overall of 36 turns for each transmitter and receiver. The thickness of each turn, as well as the distance between each turn is 0.2 $\mathrm{mm}$. The distance between the steel and the turns on each layer is $1 \mathrm{~mm}$. The coils have a length of $1.6 \mathrm{~mm}$, inner diameter of $7 \mathrm{~mm}$ and outer diameter of $11.4 \mathrm{~mm}$ with a separation of $1 \mathrm{~mm}$. Measurements of inductance were taken with an impedance analyser (Solartron 1260) at frequencies from $10 \mathrm{~Hz}$ to $1 \mathrm{MHz}$. The geometry and setup for sensor measurement is shown in Figure 2.

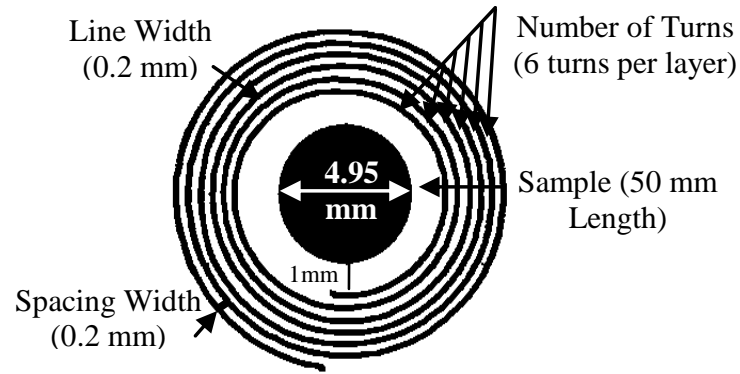

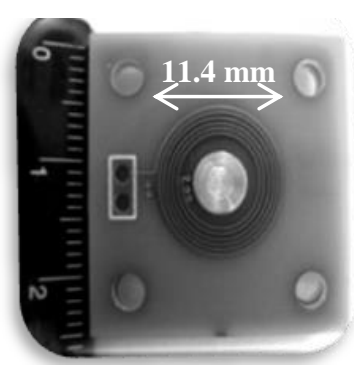

(b) (a)

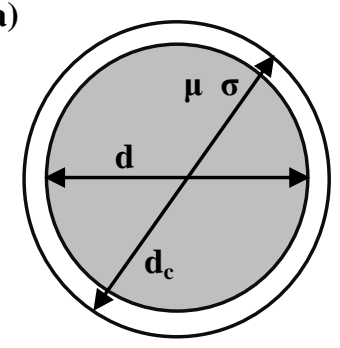

(c)
Figure 2. (a) Geometry of each layer of the coil and sample setup (b) The fabricated PCB-coil integrated sensor with 6 layers on each Receiver and Transmitter (c) The geometry of the coil and the steel sample for the example below

Assuming an infinitely long coil encircling an infinitely long cylindrical sample, an analytical solution can be established from Maxwell's Equations [12]

$$
\frac{L}{L_{\text {air }}}=1-\eta+\frac{2 \eta u_{1}}{\alpha u_{0}}\left(\frac{J_{1}(\alpha)+Y_{1}(\alpha)}{J_{0}(\alpha)+Y_{0}(\alpha)}\right)
$$

Where $\eta=d^{2} / d_{c}^{2}$ is the fill factor, $d_{c}$ is the diameter of the coil and $d$ is the diameter of the rod sample. $J_{1}$ and $Y_{1}$ are respectively, Bessel functions of the first and second kind of the first order, $V$ indicates that $Y_{0}$ and $Y_{1}$ are Imaginary Bessel function, $\mu_{0}$ is the permeability of free space, $L_{a i r}$ is the electrical impedance of the empty coil. In the limit of low frequency, i.e. when $f \rightarrow 0$ then: 
$\frac{L}{L_{\text {air }}}=1-\eta+\eta \frac{\mu}{u_{0}}$

Suppose we use the empty coil as reference, then:

$\frac{L-L_{\text {air }}}{L_{\text {air }}}=\eta\left(\frac{\mu}{u_{0}}-1\right)$

From Equation (3), it can be seen that the inductance difference has a linear relationship with the permeability of the steel sample.

The above analytical solutions are only valid for idealised geometries (i.e. infinitely long samples placed coaxially in a finite or an infinitely long coil), therefore FE models which take full account of the sensor and sample interaction were built in Maxwell 12.0 (ANSYS, Inc.) to model the actual measurement arrangement, in order to determine the relative permeability and conductivity by fitting with the experimental data. (see Figure 3).

Note $\mathrm{Z}$ is the axis of rotational symmetry.

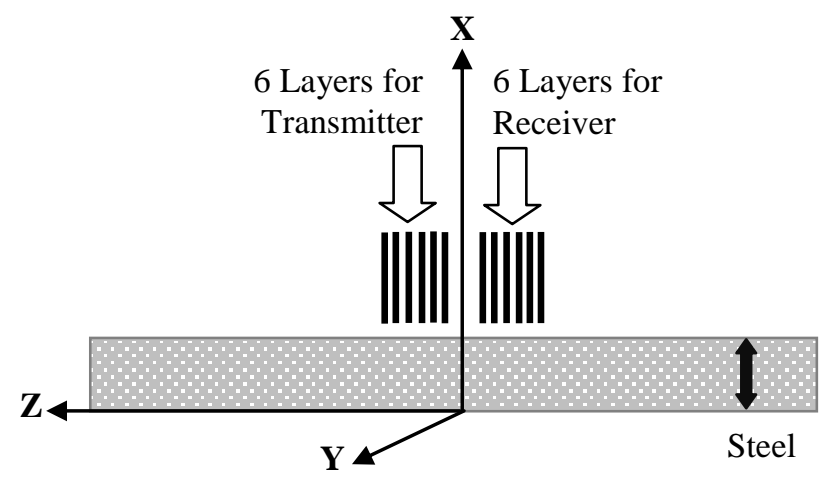

Figure 3. Axis symmetrical FE model for the sensor and sample

\section{MEASUREMENT AND EXPERIMENTAL \\ RESULTS}

\section{A. Metallographic Tests}

Complete metallographic tests and a subsequent change in the microstructure for the P9 grade samples have been analysed and presented previously [10]. However, for completeness, the microstructure of the P9 samples with different conditions has been shown in Figure 4.

The heat treated (normalised and tempered) P91 steels consist of predominantly tempered martensite, with hardness of $255 \pm 3.6$ (Vickers), as shown in Figure 5(a). After service exposure of $50,000 \mathrm{hrs}$ at $550^{\circ} \mathrm{C}$, the microstructure is slightly degenerated tempered martensite with hardness of $229.9 \pm 3.8$ (Vickers), as shown in Figure 5(b).
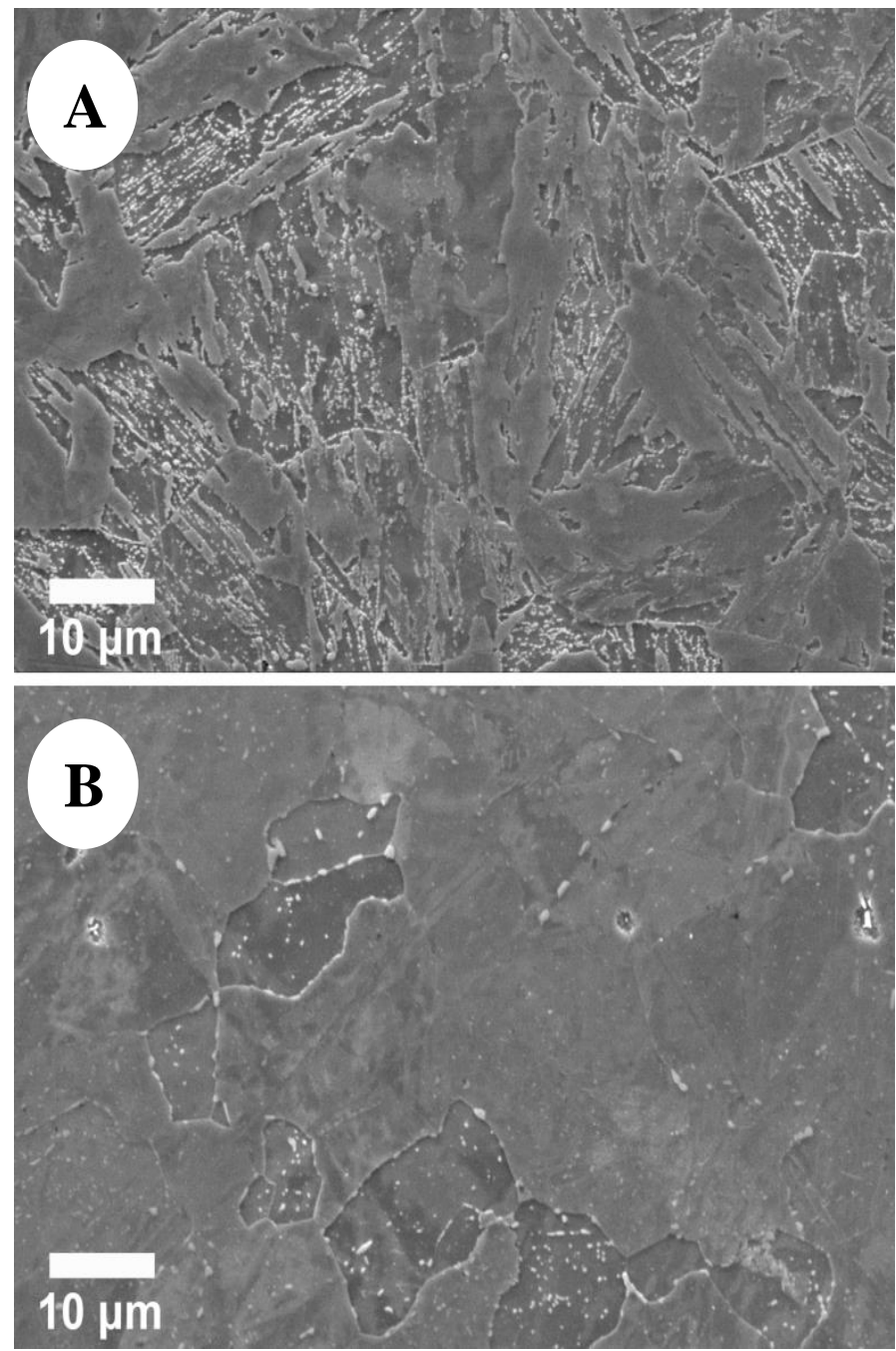

Figure 4. Microstructure of the P9 samples in different conditions: (a) as tempered and (b) ex-service

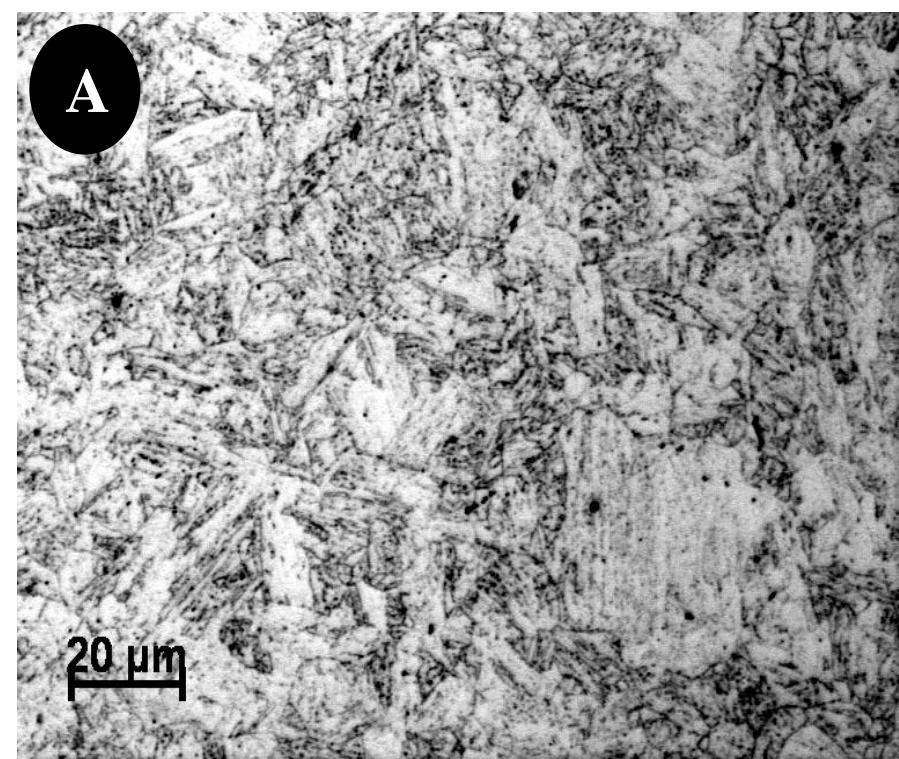




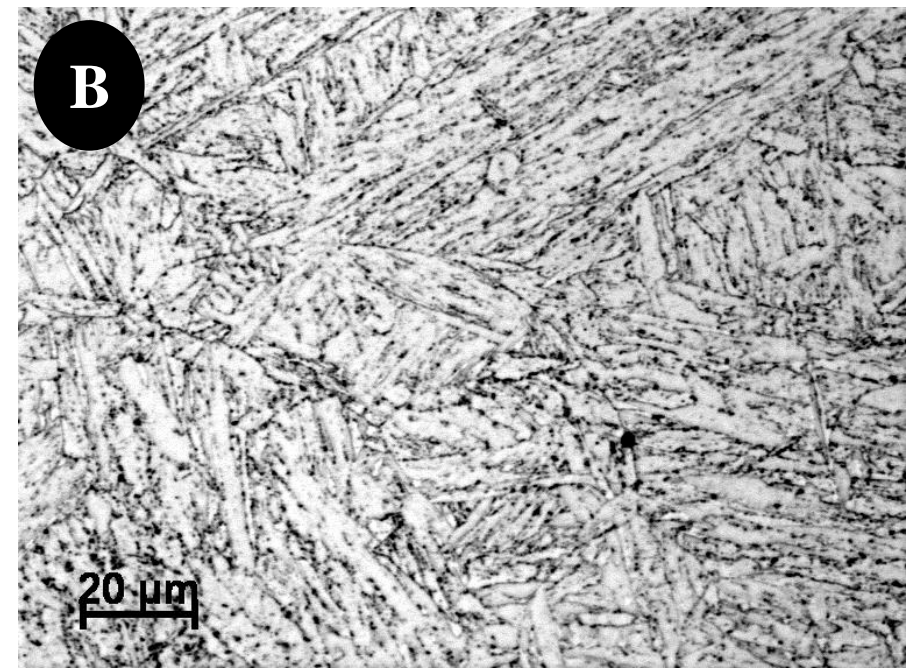

Figure 5. Microstructure of the P91 samples in different conditions: (a) as tempered and (b) ex-service

\section{B. EM Sensor Measurements}

The measured inductance spectra for P9 and P91 with different conditions are shown below.

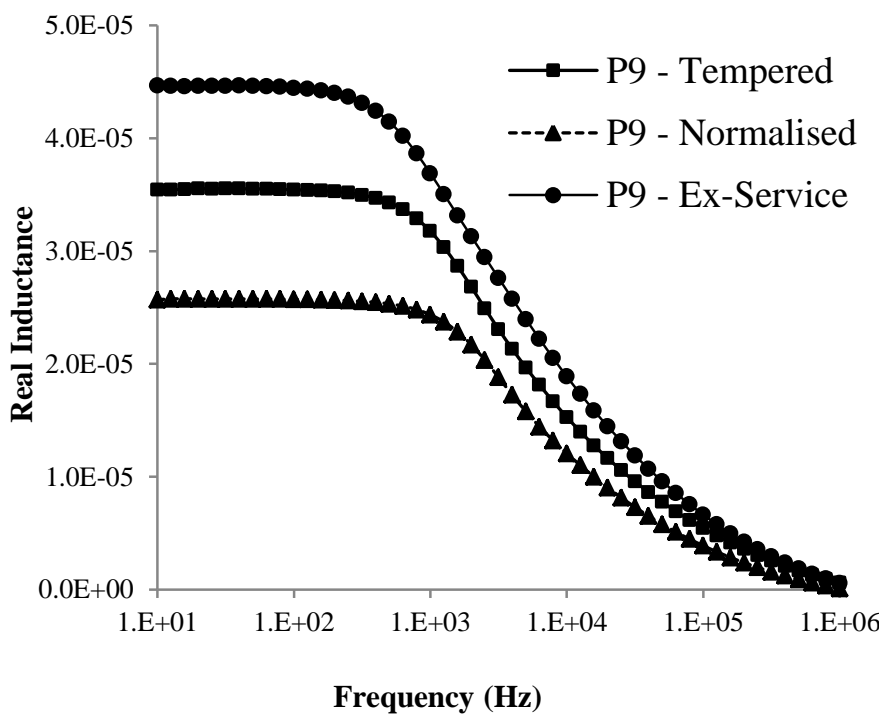

Figure 8. Inductance spectra for P9 samples of different conditions

As it can be observed from Figure 8, P9 steel samples have differences in curves for different samples, therefore the samples have different EM properties and that is consistent with different microstructures.

Figure 9 shows very similar curves for the different samples. This indicates that the EM properties for the sample in the heat treated (normalised and tempered) condition and the samples removed from service are similar suggesting the differences in microstructure (which influence the EM properties) are small. It is worth noting that the low frequency real inductance values for these samples are similar to the ex-service P9 sample, which may be due to the differences in sample geometry, as some of the P91 samples are smaller in either length or width. For example, A3 sample has length of $48.07 \mathrm{~mm}$ and D1 and D2 have width of $4.08 \mathrm{~mm}$ and $4.09 \mathrm{~mm}$ respectively.

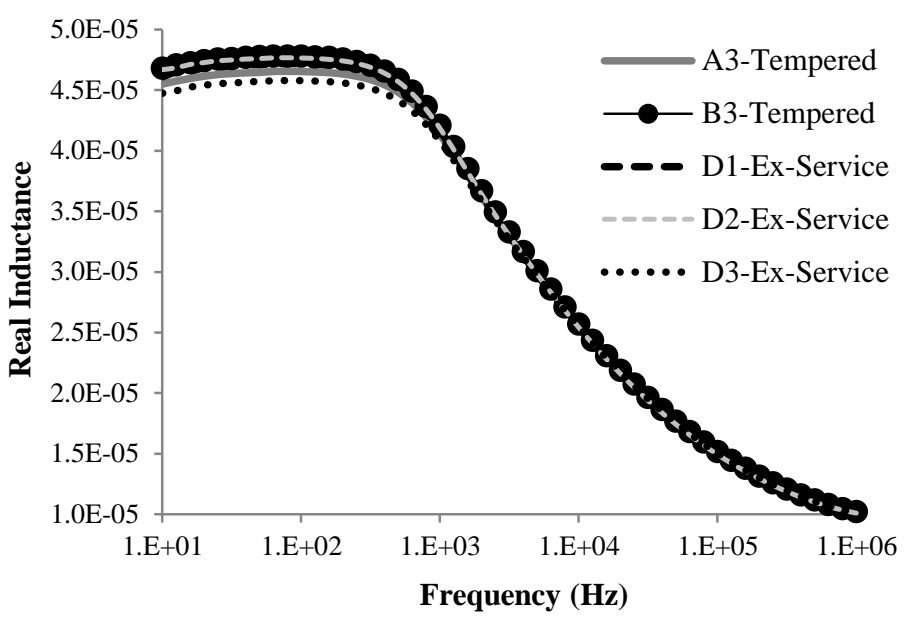

Figure 9. Inductance spectra for P91 samples of different conditions

\section{B-H Measurements}

Another aspect of obtaining the magnetic properties for a sample is to measure its magnetic hysteresis. The B-H curves for the three P9 steel samples with different conditions have been measured. The reason for such measurement is to obtain the relative incremental permeability of these power station steels through their magnetic hysteresis, results of which can be connected to the permeability values obtained from the spectroscopy of these samples. The setup for such measurement is presented in Figure 6.

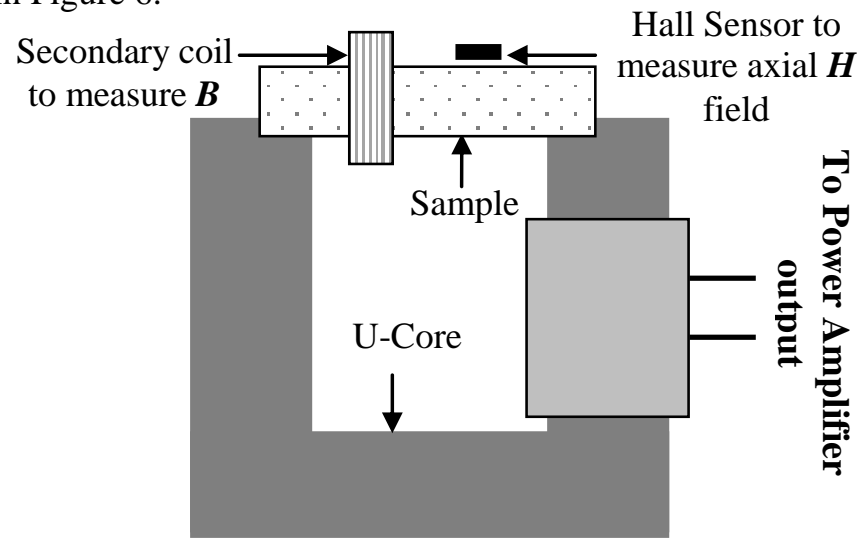

Figure 6. Setup for the B-H measurements

The B-H curves for three P9 samples with different degrees of degradation are illustrated in Figure 7. As it can be seen from figure below, different power station sample has 
different $\mathrm{BH}$ curves. The $\mathrm{B}-\mathrm{H}$ curves demonstrate the micro-magnetic properties of steels including coercivity, remanence, saturated magnetisation etc. These properties and the relative permeability can be affected by different microstructural features therefore $\mathrm{B}-\mathrm{H}$ measurement and EM sensor can be complementary techniques.

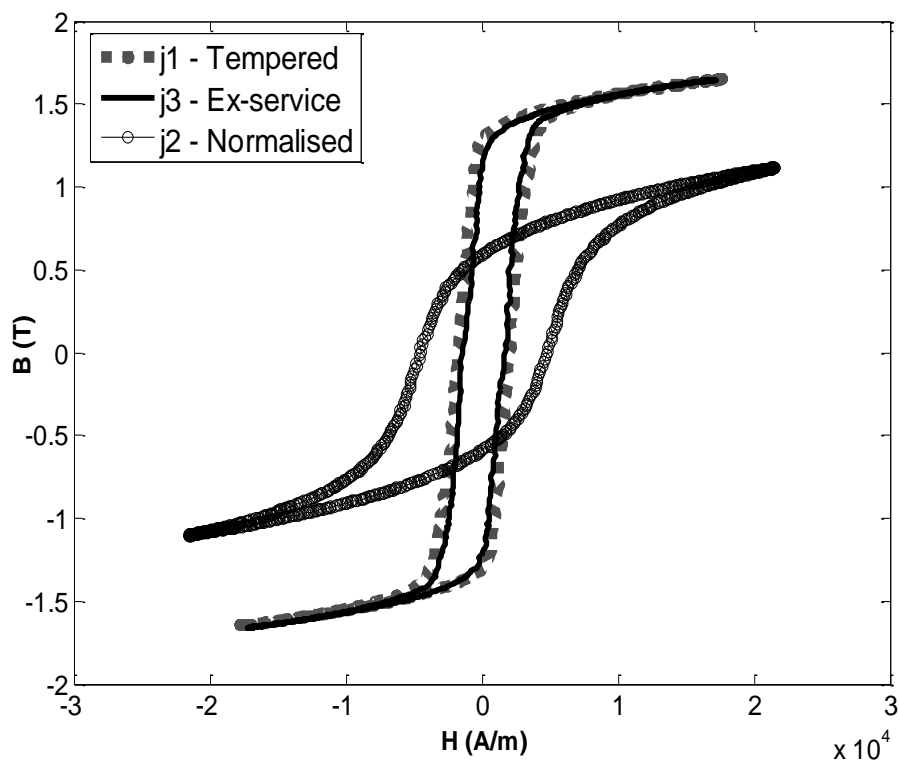

Figure 7. B-H measurements for P9 samples with different conditions (The two similar curves are the dotted gray line for $\mathrm{J} 1$ and solid black line for $\mathrm{J} 3$ )

\section{Permeability and Conductivity Evaluation}

Finite element models were setup to simulate the sensor response. The simulated results are compared to the measured results to fit the conductivity and permeability in a least squared sense.

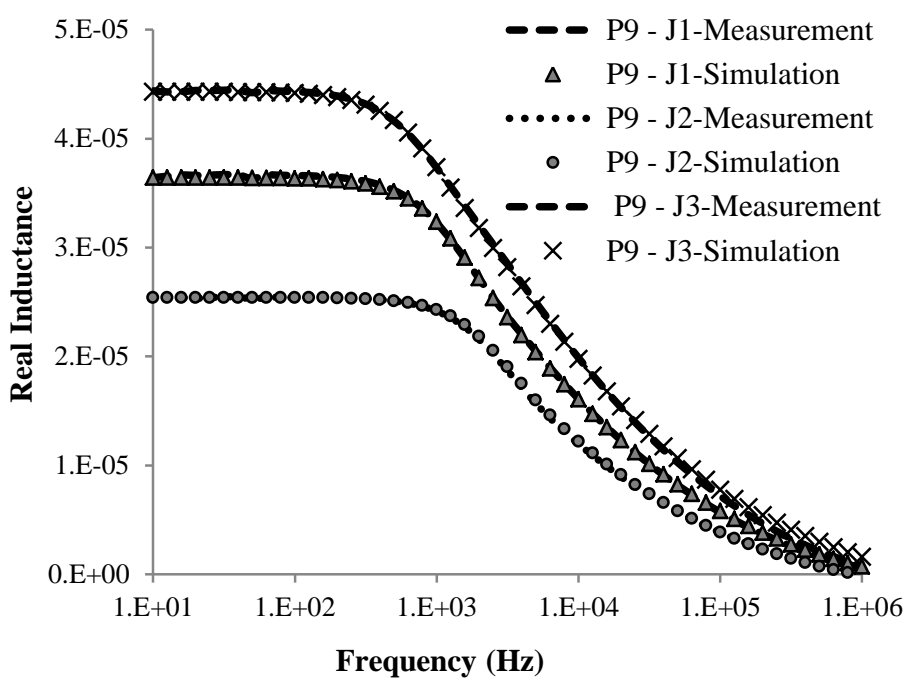

Figure 10. Fitting for P9 samples; comparison of the simulated results with the measured results (dotted lines for measurements and markers for simulation)

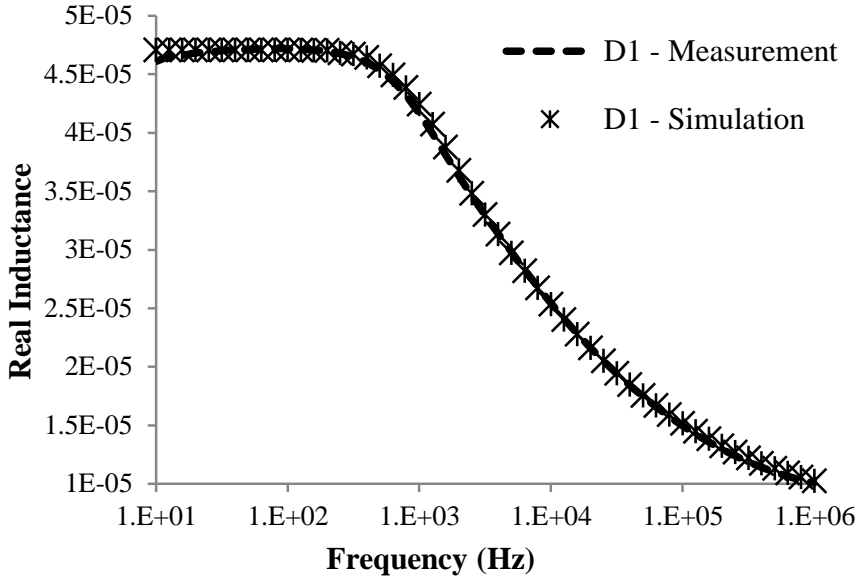

Figure 11. Fitting for one of the P91 samples (D1); comparison of the simulated results with the measured results (dotted lines for measurements and markers for simulation)

It is apparent from figures 10 and 11 that the measurement and simulation results are in good agreement. The permeability and conductivity for the P91 and P9 samples can therefore be inferred, list of which is provided in Table 1.

Table 1. Summary of the relative permeability and conductivity values for different P9 and P91 steel samples

\begin{tabular}{|c|c|c|c|c|}
\hline \multicolumn{3}{|c|}{ Samples and conditions } & $\begin{array}{c}\text { Relative } \\
\text { Permeability }\end{array}$ & $\begin{array}{l}\text { Conductivity } \\
\text { (MS/m) }\end{array}$ \\
\hline \multirow{5}{*}{$\bar{\AA}$} & A3 & \multirow{2}{*}{$\begin{array}{l}\text { Normalised at } \\
1080{ }^{\circ} \mathrm{C} \text { for } 1 \\
\text { hour followed by } \\
\text { tempering at } 760 \\
{ }^{\circ} \mathrm{C} \text { for } 1 \text { hour - } \\
\text { Bulk }\end{array}$} & 64 & 2.10 \\
\hline & B3 & & 71 & 2.10 \\
\hline & D1 & $\begin{array}{l}\text { Ex - Service } \\
\text { Inner surface }\end{array}$ & 68 & 2.10 \\
\hline & D2 & $\begin{array}{c}\text { Ex - Service } \\
7 \mathrm{~mm} \text { off surface }\end{array}$ & 71 & 2.10 \\
\hline & D3 & $\begin{array}{c}\text { Ex - Service } \\
\text { Bulk }\end{array}$ & 69 & 2.10 \\
\hline \multirow{3}{*}{$\widehat{\varrho}$} & $\mathrm{J} 1$ & $\begin{array}{l}\text { Normalised and } \\
\text { Tempered at } \\
760^{\circ} \mathrm{C} \text { for } 1 \mathrm{~h}\end{array}$ & 62 & 1.82 \\
\hline & $\mathrm{J} 2$ & $\begin{array}{l}\text { Normalised at } \\
950^{\circ} \mathrm{C} \text { for } 1 \mathrm{~h}\end{array}$ & 29.5 & 1.69 \\
\hline & $\mathrm{J} 3$ & $\begin{array}{l}\text { Taken from } \\
\text { service }\end{array}$ & 109 & 1.83 \\
\hline
\end{tabular}

It is interesting to see how the values for P9 and P91 normalised, tempered and ex-serviced samples increase from small to large values respectively.

By comparing the metallographic observation presented in figures 4 and 5 and the magnetic permeability values presented in Table 1, it can be seen that the ex-service P9 
sample, with equiaxed ferrite with large carbides distributed within ferrite grains or on grain boundaries, has a higher magnetic permeability value. On the other hand, the samples with large amount of martensite / bainite produce a lower magnetic permeability Therefore, there is a correlation between the metallographic observations and the obtained magnetic properties for these materials.

It is also evident that when a series of samples all have basically similar metallurgical microstructure, i.e. all the P91 samples and $\mathrm{J} 1$, which are all forms of tempered martensite, then the variation in permeability is very small. Thus, all the permeability values for P91 samples fall into a narrow range 64-71. The permeability result for the P9 sample $\mathrm{J} 1$ is 62 which is also within much the same range, despite its different composition. However, when there is a change of microstructural type, there is a big change in permeability. As a result, the sample with un-tempered martensite (J2) has permeability of 29.5 and the sample with ferritic structure (J3) has permeability of 109 .

Of course this paper has only considered one ferritic high alloy steel and one un-tempered martensitic high alloy steel, so for verification, it will be important to study more such examples.

\section{E. Sensitivity and Error Analysis}

A complete sensitivity and error analysis on the permeability values of these power station steels, obtained from the spectra has been assessed by the present authors in $[10,11]$.

\section{CONCLUSIONS AND DISCUSSION}

In this paper, the B-H measurements of $\mathrm{P} 9$ power station steel samples were initially presented. Results for P91 and P9 cylindrical power station steel samples with different microstructural conditions using a non-contact multifrequency EM sensor are also presented. The relative permeability and conductivity of samples were inferred by fitting FE models to the measured spectra. It was found that the EM sensor results, determined by the steel EM properties, are affected by the microstructure, therefore for the samples investigated and presented in this paper, a clear difference in signal for the different microstructures (normalised only, normalised and tempered and ex-service) can be seen.

\section{Acknowledgement}

The authors greatly acknowledge the financial support of The Engineering and Physical Sciences Research Council (EPSRC) for this project under contract EP/ /H022937. We would also like to thank E.ON for supplying the P91 steel samples used in this study.

\section{REFERENCES}

[1] Ma. X., Peyton. A.J., and Zhao. Y.Y., "Eddy current measurements of electrical conductivity and magnetic permeability of porous metals," NDT\&E International 2006; Volume 39: 562-568.

[2] Haldane. R.J., Yin. W., Strangwood. M., Peyton. A.J., Davis. C.L., "Multi-frequency electromagnetic sensor measurement of ferrite/austenite phase fractionExperiment and theory," Scripta Materialia 2006; Volume 54: 1761-1765.

[3] Yin. W., Peyton. A. J., Strangwood. M., Davis. C. L., "Exploring the relationship between ferrite fraction and morphology and the electromagnetic properties of steel," Mater. Sci. 2007; Volume 42: 6854-6861.

[4] Hao. X.J., Yin. W., Strangwood. M., Peyton. A.J., Morris. P.F. and Davis. C.L., "Off-line measurement of decarburization of steels using a multifrequency electromagnetic sensor," Scripta Materialia. 2008; Volume 58: 1033-1036.

[5] Papaelias. M.P.H., Strangwood. M., Peyton. A. J., and Davis. C.L., "Measurement of phase transformations in steel using electromagnetic sensors," Journal of Ironmaking and Steelmaking 2002; Volume 29 (6): 469-476.

[6] Sposito. G., Ward. C., Cawley. P., Nagy. P. B., Scruby. C., "A review of non-destructive techniques for the detection of creep damage in power plant steels," NDT\&E International 2010; Volume 43: 555-567.

[7] Gou. R., Zhang. Y., Xu. X., Sun. L., Yang. Y., "Residual stress measurement of new and in-service X70 pipelines by X-ray diffraction method," NDT\&E International 2011; Volume 44: 387-393.

[8] Kahrobaee. S., Kashefi. M., "Hardness profile plotting using multi-frequency multi-output electromagnetic sensor," NDT\&E International 2011; Volume 44: 335338.

[9] Ennis. P., Czyrska-Filemonowicz A., Recent Advances in Creep Resistant Steels for Power Plant Applications, Sadhana Acad. Proc. Eng. Sci. 28 (2003) 709-730

[10]W. Yin , N. Karimian, J Liu, X. J. Hao, L Zhou, A. J. Peyton, M. Strangwood, C. L. Davis, (May 2012); Measurement of Electromagnetic Properties of Power Station Steels; I2MTC 2012, IEEE International; pp. $1603-1606$

[11]W. Yin , N. Karimian, J Liu, X. J. Hao, L Zhou, A. J. Peyton, M. Strangwood, C. L. Davis, (2012); Measurement of Electromagnetic Properties of Power Station Steels; NDT \& E International Journal; Volume 51; pp. 135-141

[12]Libby HL. Introduction to electromagnetic nondestructive test methods. New York: Wiley; 1971 